\title{
Construindo uma nova proposta pedagógica no curso de enfermagem da Universidade Estadual de Londrina
}

\author{
Setting up a new pedagogical in the Nursing course at the State University of Londrina
}

\author{
Christine Baccarat de Godoy ${ }^{1}$ \\ Nadia Aparecida de Souza²
}

\begin{abstract}
Resumo: O estudo teve como objetivo determinar as perspectivas e dificuldades, dos docentes do Departamento de Enfermagem do Centro de Ciências da Saúde da Universidade Estadual de Londrina, na construção e implantação do Módulo I, do Currículo Integrado de Enfermagem. A pesquisa se constituiu em um Estudo de Caso e os dados foram obtidos através de questionário aplicado a 13 (treze) docentes que construíram e implementaram o Módulo I, do Currículo Integrado do Curso de Enfermagem, da Universidade Estadual de Londrina, no ano de 2000. A análise dos dados possibilitou determinar os fatores facilitadores e dificultadores na implementação do processo, bem como, levantar a percepção dos docentes sobre o processo de mudança curricular. O estudo, ao fornecerem indicadores de mudança, contribuem para a melhoria da qualidade do ensino na consecução do novo currículo de Enfermagem da Universidade Estadual de Londrina.
\end{abstract}

Palavras-chave: currículo integrado de enfermagem, Enfermagem, educação em enfermagem, mudança curricular.

Abstract: The main purpose of this article is to outline the history of the Nursisng Curriculum of the State University of Londrina, from 1972 until the present Curriculum which was implemented in January, 2000. The study is based on a bibliographic research and the result has enabled us to outline all the changing process of the curriculum considering the professors worries and the market demands. The study has contributed to a better understanding of the pedagogical proposal that forms the present Integrated Curriculum of the Nursisg Course of the State University of Londrina.

Key words: curriculum; Nursing; Nursisng Course; Curriculum Modification.

\section{Contemplando o Passado}

O Curso de Graduação em Enfermagem, da Universidade Estadual de Londrina (UEL) foi implantado em 1972 pela Resolução UEL n.․53, de 26 de março de 1971 e tem passado por sucessivas reformulações curriculares, resultantes, sempre, de amplas discussões e reflexões, orientadas pelo compromisso com a melhoria da qualidade do ensino e da prestação dos serviços de saúde à população (UEL, 1999, p.3) .

Por ocasião de sua implantação, em 1972, o curso, então, com duração de três anos, era ofertado em sistema seriado. Em 1973, sua oferta passou para o sistema de créditos.

Entretanto, as alterações não se limitaram ao sistema de oferta, foram mais amplas e profundas visando a atender orientações que emergiam do Conselho Federal de Educação. Nesse período, foram apresentados o Parecer n. $.163 / 72$ e a Resolução n.. 04/72, que aprovaram o currículo mínimo para o curso de Enfermagem, caracterizado por um ciclo básico, um tronco profissionalizante e três diferentes habilitações: Enfermagem em Saúde Pública, Obstétrica e MédicoCirúrgica. As habilitações, não obrigatórias, poderiam vir a ser cursadas pelo aluno após o término da graduação.
A organização da proposta curricular, segundo o definido pelo Conselho Federal de Educação, fez com que o ciclo básico passasse a consumir quase $50 \%$ da carga horária total do curso, em detrimento do tronco profissionalizante, o que gerou enorme preocupação quanto às reais possibilidades do egresso no desempenho profissional e terminou por determinar uma segunda mudança curricular, discutida e esboçada durante o I Fórum de Debates sobre o Curso de Enfermagem da Universidade Estadual de Londrina, realizado em 1977, que estabeleceu os limites e possibilidades da alteração curricular promovida em 1980.

Nessa segunda reformulação curricular, a duração do curso foi ampliada para três anos e meio e destinouse maior carga horária para as disciplinas profissionalizantes. Mas, apesar das alterações promovidas, permaneceu a dicotomia entre teoria e prática em virtude da segmentação entre disciplinas teóricas e estágios.

No decorrer da década de 80 (oitenta), ocorreram mudanças na política de saúde do país. As novas demandas que se interpunham ao setor foram analisadas e discutidas na $8^{\underline{a}}$ Conferência Municipal de Saúde, ocorrida em 1988. Os serviços de saúde procuravam se reorganizar e, com isto, criar novos mercados de trabalho para o enfermeiro.

\footnotetext{
${ }^{1}$ Enfermeira especialista em Metodologia da Ação Docente pela Universidade Estadual de Londrina, docente do Departamento de Enfermagem da Universidade Estadual de Londrina.

2 Doutora em Educação pela Universidade Estadual Paulista, docente do Departamento de Educação da Universidade Estadual de Londrina e integrante do Núcleo de Estudos e Pesquisas em Avaliação Educacional.
} 
Essa nova realidade veio fomentar uma inquietude crescente junto àqueles que atuavam no ensino de enfermagem, pois evidencia-se, então, a necessidade de superar a desvinculação existente entre o processo de formação e a realidade prática, de maneira a efetivamente atender as necessidades da sociedade na preparação de recursos humanos para atuar na área de saúde.

Buscando soluções, foram realizados seminários nacionais e regionais, encontros, fóruns e debates, promovidos pela Associação Brasileira de Enfermagem (ABEN) e pelo Curso de Enfermagem da UEL. Assim, o período de 1989 a 1990 foi rico em reflexões e análises que objetivavam a superação das muitas dificuldades diagnosticadas na formação do profissional de enfermagem.

Um olhar para o passado, tentando melhor compreendêlo no confronto com as muitas demandas que emergiam da nova realidade social, econômica e política que se delineava no país, possibilitou tracejar o perfil do profissional a ser formado para atuar no futuro. Assim, o estudo Análise Prospectiva do Curso de Graduação em Enfermagem na UEL (CHRISTOFOLLI, 1990; MAGALHÃES et al., 1993), apresentou subsídios para a nova reformulação curricular, extremamente necessária, então.

Foi promovida a terceira mudança curricular, implantada em 1992. Dentre as alterações mais relevantes, destacam-se a ampliação do curso para quatro anos e a criação do internato de enfermagem no último semestre do curso. A inclusão do internato atendia uma série de preocupações e permitia a consecução de variados objetivos, como:

[...] promover a melhoria da qualidade de ensino e assistência de enfermagem, bem como iniciação científica, criando oportunidades de ensino e aprendizagem que possibilitem a vivência de situações profissionais e o aprofundamento de conhecimentos nas áreas básicas de atuação do enfermeiro (UEL, 2000, p.3).

Contribuindo para essas mudanças curriculares, destaca-se o incentivo do Projeto UNI (uma nova iniciativa para a educação dos profissionais de saúde: União com a Comunidade), implantado em 1991 e financiado pela Fundação W. K. Kellogg, que tem atuado no setor de saúde da América Latina desde 1942, apoiando movimentos e propostas de reforma do ensino na saúde. Os princípios do projeto UNI são:

[...] interdisciplinaridade, prática multiprofissional, inserção precoce do aluno na rede de serviços de saúde e na comunidade, ensino centrado no aluno e professor com papel de orientador da aprendizagem, integração do ensino da área básica com a da profissionalizante, ensino e pesquisa orientados pelos problemas prioritários de saúde da população, articulação do ensino, pesquisa e assistência (UEL, 1999, p.6).

Em 1994, o Ministério da Educação e do Desporto, através da Portaria $n . \stackrel{0}{1721}$, de 15 de dezembro de
1994, estabeleceu um novo currículo mínimo para o Curso de Enfermagem e definiu o perfil do enfermeiro generalista, ou seja, com visão não fragmentada de sistemas e especialidades, mas com visão holística e, ainda, com formação para atuar em quatro áreas fundamentais: assistência, gerência, ensino e pesquisa.

A proposição dessa resolução obrigou o repensar do Curso de Enfermagem e suscitou a quarta mudança curricular, implementada em 1996.

Para atender a essa nova proposta curricular, o Colegiado de Curso promoveu oficinas de trabalho e atividades para aperfeiçoamento didático do corpo docente. Destacam-se, nesse processo de transformação curricular, algumas iniciativas como a criação do (Núcleo de Apoio Pedagógico, (NAP) implantado em 1994, com a finalidade de proporcionar orientação, assessoria e capacitação pedagógica aos docentes da área de saúde), o projeto PEEPIN (Projeto Especial de Ensino em Assistência Primária à Saúde -- Práticas Multiprofissionais e Interdisciplinares, destinado aos alunos do primeiro ano dos cursos do Centro de Ciências da Saúde, desenvolvido através da Metodologia da Problematização, levando grupos de alunos de diferentes cursos a trabalharem em equipe nas Unidades Básicas de Saúde) e o programa Programa de Apoio a Projetos de Pesquisa na área de Saúde de Londrina, (PAPP) implantado em 1994, (financiando projetos de pesquisa), o que veio diversificar os cenários da aprendizagem para alunos, docentes, profissionais dos serviços e membros da comunidade. Assim,

[...] o processo de concepção do currículo pleno envolveu, em suas etapas iniciais, discussões sobre os princípios, crenças e valores que deveriam nortear a formação do enfermeiro e atender às necessidades do mercado de trabalho, sem perder de vista a capacidade da crítica, reflexão e intervenção sobre o mesmo (HIRAZAWA ,1998, p.16).

Contudo, tornou-se necessário avaliar este currículo frente às expectativas do mercado de trabalho, envolvendo, nessa reflexão os docentes do ciclo básico e do profissionalizante, representantes discentes, profissionais dos serviços de saúde e de associações de classe específicas.

Percebeu-se, no decorrer das oficinas e dos grupos de reflexão, que a predominância do ensino tradicional, a prevalência da formação técnica voltada para ações curativas (visão biologicista), a desarticulação entre teoria e prática, a fragmentação em ciclo básico e clínico, a inadequação de carga horária para algumas disciplinas, a seleção de conteúdos sem parâmetros claros, a preocupação excessiva com a transmissão do conhecimento em detrimento da qualidade do processo de aprendizagem, a inserção inadequada de algumas disciplinas na grade curricular, a fragilidade na relação com os serviços e o número excessivo de alunos por turmas (BOGADO, 1998), não preparavam 
o enfermeiro para a capacidade gerencial com competência para as ações de promoção e prevenção em saúde, exacerbando a dicotomia entre o ensino e a prática.

Diante deste diagnóstico, estabeleceu-se que a meta para o ensino de enfermagem deveria ser

[...] a formação de um profissional consciente de sua responsabilidade histórica, traduzida pela reflexão crítica da sociedade e da prática de assistência à saúde, na perspectiva de redirecionamento dessa prática a partir de seu compromisso com o contexto social e com os reais interesses da comunidade (TAKAHASHI et al., 1995. p. 58).

Para tentar superar, pelo menos parcialmente, os problemas identificados e permitir a adequada preparação do corpo docente para novas alternativas de ensino, foi desencadeada a quinta mudança curricular, chamada de Currículo de Transição, que vigorou de 1996 a 1999. Esse currículo foi estruturado a partir do eixo saúde-doença, estreitando as relações entre as disciplinas básicas e profissionalizantes, integrando ensino com serviço e buscando alternativas metodológicas que estimulassem a participação ativa do aluno no processo de ensino e aprendizagem.

Paralelamente, o Internato de Enfermagem, planejado e operacionalizado no auge das discussões do currículo de 1996, acabou absorvendo e refletindo em seus objetivos e processo de viabilização as diretrizes, metas, eixos norteadores e perfil expressos na proposta curricular de 1996 (SOUZA, 1999).

Assim, o internato é descrito como "[...] uma experiência ímpar no processo de formação dos alunos e na articulação/integração entre as práticas de ensino e de serviço, favorecendo ao aluno uma vivência mais próxima da realidade de trabalho que o espera [...]" (VANNUCHI et al., 1996, p.14).

O Currículo de Transição, avaliado pelo Colegiado do Curso de Enfermagem três anos após sua implantação, trouxe a adoção de outras estratégias de ensino, como estudos de caso, Metodologia da Problematização, discussão teórica a partir da prática, estudos bibliográficos, visitas domiciliares, visitas aos serviços de saúde, realização de painéis integrados envolvendo disciplinas do básico e profissionalizante, realização de seminários integrados, elaboração de programa de conteúdos teóricos com a participação dos alunos em projetos de ensino (Peepin e Papiens) ${ }^{3}$, de extensão e de pesquisa, diminuindo a distância entre

\footnotetext{
${ }^{3}$ Práticas Multiprofissionais e Interdisciplinares / Programa de Apoio a Projetos Integrados de Ensino e Serviço de Saúde, projetos baseados na interdisciplinaridade, no trabalho em equipe multiprofissional, na pesquisa inserida na comunidade e na diversificação dos cenários de aprendizagem, com o objetivo de estimular o desenvolvimento de novos modelos acadêmicos e de assistência à saúde de uma forma integrada, financiando projetos integrados de ensino e serviços de saúde.
}

teoria e prática e buscando novos campos de estágio. Mas, as mudanças são maiores e acontecem também pela promoção e realização de novas formas de avaliação, progressivamente voltadas para a finalidade diagnóstica que, valendo-se de diferentes instrumentos, foram apontadas pelos alunos como facilitadoras do processo de aprendizagem.

Todavia, tais mudanças aconteceram ainda por iniciativa de algumas disciplinas e não no curso, como um todo.

Em estudos promovidos pelo Colegiado de Enfermagem, em 1998, os alunos solicitaram a aplicação de metodologias que incentivassem a pesquisa e a aprendizagem de forma ativa, assim como a introdução de mudanças maiores nas estratégias de ensino para que eles pudessem conhecer a realidade de trabalho do enfermeiro, percebendo melhor as características de seu campo de atuação e as particularidades da atuação em equipe multiprofissional.

Dando continuidade ao processo de discussão e transformação curricular e pautando-se nos princípios da nova Lei de Diretrizes Básicas da Educação Nacional, implantou-se, em janeiro de 2000, o Currículo Integrado cuja estrutura segue a criação de módulos integrados que viabilizam a interdisciplinaridade e a relação teoria-prática, adotando a Metodologia da Problematização e com o objetivo de formar alunos críticos, criativos e ativos, que constroem seus conhecimentos a partir da realidade e são protagonistas conscientes na construção das transformações desejadas, estando a pesquisa inserida neste processo.

A nova proposta pedagógica fundamenta-se na certeza de que o aluno é sujeito ativo no processo de construção do seu conhecimento, cumprindo ao professor a condução dos processos de ensino e aprendizagem pelo permanente desafiar do raciocínio do aluno e pela progressiva integração de novos conhecimentos às experiências prévias. 0 conteúdo passa a ser organizado através de sucessivas aproximações e em níveis crescentes de complexidade.

Os eixos norteadores desta mudança foram (UEL, 1999, p.3):

- Estruturação a partir do eixo saúde-doença;

- Integração ensino, serviço e comunidade;

- Articulação entre teoria e prática;

- Interdisciplinaridade;

- Trabalho em equipe multiprofissional;

- Formação do enfermeiro generalista;

- Terminalidade na graduação.

O novo currículo propõe a formação de um profissional capaz de "[...] prestar e gerenciar a assistência de enfermagem com conhecimentos, habilidades e atitudes que poderão influenciar nas decisões políticas e organizacionais na área da saúde [...]" (UEL,1999, p.3), pretendendo, desta forma, atender as exigências do mercado (com ações assistenciais, gerenciais, de pesquisa e educação) e acompanhando as mudanças nos contextos social, cultural, político e econômico do país. 


\section{Vislumbrando o Presente}

\subsection{Perfil do enfermeiro a ser formado}

Com a implementação do Currículo Integrado, o Curso de Enfermagem da Universidade Estadual de Londrina pretende formar profissionais que desempenhem uma prática comprometida com as necessidades de saúde da população, demonstrando em seu exercício autonomia, iniciativa, ética, raciocínio investigativo, criatividade, capacidade de comunicação, capacidade de resolução de problemas e de trabalho em equipe interdisciplinar e multiprofissional, valorizando, acima de tudo, o ser humano e a profissão.

Desta forma, o curso tem por objetivos formar o enfermeiro para (UEL, 1999, p. 15):

- Prestar assistência de Enfermagem ao indivíduo, família e comunidade, nos diferentes níveis de atenção à saúde, utilizando metodologia científica;

- Gerenciar a assistência de Enfermagem em todas as áreas de atuação;

- Respeitar os princípios éticos e legais da profissão, valorizando o ser humano em sua totalidade e o exercício da cidadania;

- Relacionar o processo de saúde e doença e o cuidar com a história sócio-cultural do ser humano;

- Refletir criticamente sobre a prática da Enfermagem, considerando as determinantes éticas, políticas, econômicas e sociais que a influenciam;

- Exercer função integrativa na comunidade, no serviço, e na equipe de saúde e de Enfermagem;

- Atuar como agente multiplicador de conhecimentos, reconhecendo o seu papel de educador;

- Desenvolver continuamente a capacidade de trabalhar em equipe interdisciplinar e multiprofissional;

- Apropriar-se do conhecimento científico aplicandoo em seu ambiente de trabalho e na comunidade;

Realizar pesquisas para aperfeiçoamento do processo de trabalho em saúde.

Para a formação de um profissional sintonizado com o redirecionamento da política de saúde e com as variações no perfil epidemiológico, se fez necessária a elaboração e implementação de uma proposta inovadora, que contemplasse não somente a grade curricular, mas que investisse em uma perspectiva pedagógica que permitisse uma ação educativa mais global e mais crítica.

\subsection{Fundamentação teórica}

A proposta pedagógica que fundamenta o Currículo Integrado articula, dinamicamente, a atuação profissional e o ensino, a prática e a teoria, a academia, o ensino e a comunidade, deixando de centrar-se nas disciplinas e passando a valorizar os processos ou fenômenos importantes para a formação do profissional de maneira integrada.

O processo de ensino e aprendizagem, nessa nova proposta, tem como eixos norteadores:

[...] a construção da cidadania, a transformação do modelo assistencial, a integração entre ensino, serviço e comunidade, a ética e o humanismo, a associação entre teoria e prática contemplando a ação e a reflexão, a transformação das práticas, a qualidade de assistência, o raciocínio investigativo, o estudo do homem a partir do núcleo familiar, a avaliação como processo e as experiências de ensino e aprendizagem estruturadas a partir do adulto para a criança (UEL, 1999, p. 12 ).

A filosofia desta concepção de ensino converge para a construção dos conhecimentos pelo aluno ao longo de sua vida acadêmica, preparando-o para o exercício profissional fundamentado em reflexão profunda, análise crítica, capacidade de tomada de decisões e competência na resolução de problemas de forma crítica e integrada à realidade social e profissional (UEL, 1999, p. 12).

Baseada em concepção crítico-social e respaldada pela pedagogia problematizadora, esta proposta veio romper com o ensino tradicional, marcado pela passividade e falta de atitude crítica do aluno, bem como pela distância entre teoria e prática, condicionantes que trazem para o dia a dia, quer na prática profissional, quer no exercício da cidadania, conseqüências como conformismo, submissão à dominação, individualismo, falta de participação e adoção indiscriminada de modelos de pensamento (DIAZ BORDENAVE, 1983).

Destarte, o processo de ensino deve desenvolver no aluno o seu potencial político-social, juntamente com o seu potencial intelectual, promovendo o pleno desenvolvimento de seus saberes teóricos e práticos para o exercício profissional, formando o indivíduo como sujeito livre e autônomo (FLEURI, 1997) e fazendo da educação uma responsabilidade social e política (FREIRE, 1971). Para tanto, se faz necessário mudar as perspectivas da sala de aula, com a construção de propostas de ensino inovadoras.

Assim, a prática pedagógica, longe de reproduzir o já existente, deve, antes de tudo, colaborar "[...] para a transformação capaz de trazer melhores condições de vida para o homem em sociedade" (BERBEL, 1996, p. 38).

Para que a educação possa realmente assumir o seu papel nesta construção se faz necessário romper com o saber e o conhecimento autoritários, afastandose do modelo segundo o qual o educador é a figura que centraliza todos os desejos, conhecimentos e possibilidades de ação. A escola precisa cumprir suas finalidades e se reinventar para efetivamente contribuir na formação do futuro profissional, ciente de seus direitos e de suas responsabilidades (GROSSI, 1993).

No contexto da educação problematizadora, é preciso definir o sujeito do processo pedagógico, quais os objetivos perseguidos no processo educativo (habilidades, atitudes, tipo de profissional / homem / sociedade que se pretende formar) e como educar (estratégias / metodologia) (FLEURI, 1997).

Nessa concepção, o aluno é o sujeito do processo e o ensino deve ser baseado nas suas vivências e experiências, no que ele observa no dia a dia, estimulando 
a reflexão lógica e a reflexão empírica (FLEURI, 1997), situando o educando como protagonista do processo pedagógico e a educação, como libertadora do ser humano, voltada para a transformação da realidade.

Sob essa nova perspectiva, as experiências anteriores do aluno fornecem elementos importantes para que ele construa seus conhecimentos, assim como afirma-se essencial um constante revisitar da realidade de trabalho (MISAEL, 1995). Desta forma, a prática educacional se faz pelo próprio aluno, de dentro para fora e não de cima para baixo, como uma doação ou imposição (FREIRE, 1983).

Segundo a proposta problematizadora, portanto, o aluno é o centro do processo e o educador é o mediador que vai ajudar a explicitar e a sistematizar aquilo que a vida e o contexto dos educandos fornecem como elementos de análise, reflexão e reestruturação do saber.

A partir desta concepção, podemos compreender que a metodologia tradicional, eminentemente dedutiva, baseada na reprodução de conceitos e noções, tendo o professor como detentor absoluto do saber e tendo o real como algo a ser explicado e não transformado, rompe-se frente a uma metodologia indutiva nesta a prática social dos educandos é que constitui o eixo em torno do qual gira o processo educativo, aprofundando, progressiva e continuamente, o conhecimento do real e as suas possibilidades de transformação.

Conferindo dinamicidade e organicidade a essa prática pedagógica, temos como elementos constitutivos os COMPONENTES: HUMANOS, CULTURAIS e METODOLÓGICOS (BERBEL, 1996).

Os componentes humanos dizem respeito às relações entre professor e aluno, entre alunos e alunos e entre alunos e comunidade.

Os componentes culturais se referem às finalidades da educação, pela busca incessante de equilíbrio entre quantidade e qualidade dos conteúdos.

Por fim, os componentes metodológicos que abrangem os métodos, as técnicas, os recursos, a organização, a execução e avaliação do processo de ensino e aprendizagem vivenciado e compartilhado por todos que dele participam.

\subsection{Opção metodológica}

A Metodologia da Problematização tem por momento inicial a observação da realidade, no decorrer da qual o tema será trabalhado, seguido de reflexão na busca dos possíveis fatores que estão associados ao problema emergente da realidade sob foco.

No segundo momento, definem-se os aspectos que precisam ser conhecidos e compreendidos na busca de respostas para esse problema, assim os pontos-chave, que orientarão os estudos e análises subseqüentes, são determinados.

A seguir, procede-se ao estudo criterioso acerca dos muitos aspectos teóricos relativos aos pontos-chave estabelecidos. É, portanto, no decorrer da teorização que os alunos desvelam pressupostos e fundamentos que os orientarão na resolução do problema.

O aprofundamento teórico em confronto com a realidade possibilita a análise e discussão dos dados colhidos e a proposição de hipóteses de solução, visando intervir naquela parcela da realidade, para a superação dos problemas e dificuldades identificados.

Finalmente, as hipóteses de solução são implementadas, é o momento de aplicação à realidade, caracterizada pela ação concreta teoricamente fundamentada.

Esse método foi denominado de Método do Arco de Maguarez e foi proposto objetivando oferecer respaldo ao "[...] educador preocupado com o desenvolvimento de seus alunos e a sua autonomia intelectual, visando ao pensamento crítico e criativo [...]" (BERBEL, 1999, p. 28).

A Metodologia da Problematização permite àqueles que dela participam chegarem a uma ação prática transformadora, fruto do aprofundamento teórico em confronto com a realidade, em decorrência da elaboração de hipóteses de solução.

Nessa metodologia, a relação dinâmica entre o sujeito que aprende e o objeto do conhecimento se verifica através de sucessivas aproximações. Desta forma, o aluno tem possibilidade de aprender a pensar criticamente, desenvolvendo a capacidade de reconhecer a realidade e seus problemas, preparando-se para uma ação transformadora nos contextos profissional e social. Portanto, a Metodologia da Problematização permite ao aluno desenvolver a capacidade de construir seus conhecimentos por meio de situações observadas no contexto real, desencadeando um processo de açãoreflexão-ação, contínuo e progressivo.

Em Freire (1983) encontramos fundamentos teóricos, filosóficos e epistemiológicos para apoiar e justificar a Metodologia da Problematização, assim como em outros autores como Libâneo (1994) e Saviani (1996) que, inspirados na concepção histórico-crítica, apontam para a importância de uma pedagogia problematizadora.

Freire (1997) afirma que o aprendizado se dá somente quando o aluno se envolve profundamente com a situação, o que a metodologia da Problematização vem permitir, pois, conforme Berbel (1999), o aluno afasta-se de uma prática observada e caminha para uma nova prática, elaborada por ele mesmo, o que gera um envolvimento gradativo do sujeito com o objetivo do conhecimento.

Tanto Freire (1986) quanto Berbel (1999) afirmam ser importante levar os alunos a pensarem sobre a realidade de maneira crítica, buscando ações capazes de modificála. Para tanto, se faz necessário observar a realidade, definir o problema, levantar as suas causas e os seus determinantes, teorizar, analisar e chegar a uma nova ação. Deste processo decorre a transformação criadora, na qual se fundamenta a educação problematizadora. 
Para Diaz Bordenave (1983) e Pereira (1998) este é um processo inacabado, pois permite a todos que dele participam um contínuo e progressivo desvelamento da realidade. Para Freire (1971), uma pessoa só pode conhecer bem algo quando o transforma e transforma a si próprio no decorrer do processo de conhecimento.

Podemos perceber, então, que a Metodologia da Problematização é voltada para a transformação social e processa-se fundamentando-se na certeza de que a educação é uma atividade mediadora entre o indivíduo e a sociedade (DIAZBORDENAVE, 1983 ; SAVIANI, 1996).

Na construção do Currículo Integrado do Curso de Enfermagem, da Universidade Estadual de Londrina, foram definidos o papel do professor enquanto orientador do processo de ensino e aprendizagem, promovendo aprendizagem significativa e estimulando o raciocínio do aluno; o papel do aluno enquanto sujeito ativo no processo de construção do seu próprio conhecimento; bem como as características do conteúdo, ou seja, abordagem através de sucessivas aproximações em níveis crescentes de complexidade.

Desta forma, a Metodologia da Problematização permite alcançar os objetivos propostos pelo currículo integrado, quando possibilita formar profissionais contextualizados "[...] que aprendam na prática a transformar alguma parcela da realidade, enquanto se transformam a si mesmos em seu campo de formação acadêmica [...]" (UEL, 1999, p.15).

\subsection{Avaliação}

O novo projeto curricular do Curso de Enfermagem da Universidade Estadual de Londrina pretende formar profissionais com conhecimentos, habilidades e atitudes. Para tanto, a avaliação deve abranger todos os domínios do comportamento, quais sejam :

- COGNITIVO - referente às atividades intelectuais;

- AFETIVO - referente aos sentimentos;

- PSICOMOTOR - referente à associação da cognição com movimento corporal.

Associada ao projeto pedagógico, a avaliação deve dar dinamicidade ao processo de ensino e aprendizagem, desenvolvendo-se através da interação entre aprendiz e professor, "[...] organizando instrumentos e situações tão diversificados quanto forem necessários, em função das etapas do desenvolvimento do processo [...]" (MARCONDES, 2000, p.4).

Para atender aos novos preceitos, se torna necessário, também, avaliar o aluno não só em um momento estanque, mas em diferentes situações, no decorrer de todo o processo.

Para tanto, a avaliação deve realizar-se de modo planejado, a fim de acompanhar o desenvolvimento do educando em todas as suas etapas, diagnosticando, favorecendo a análise do processo e classificando o desenvolvimento do educando, objetivando sempre a formação do perfil profissional que se deseja.
A avaliação no Currículo Integrado se dá de forma DIAGNÓSTICA, FORMATIVA e SOMATIVA.

A avaliação diagnóstica tem por objetivo "[...] identificar eventuais problemas de aprendizagem e suas possíveis causas, numa tentativa de saná-los [...]" (MARCONDES, 2000, p. 06), ocorrendo no início do processo para constatar os conhecimentos e habilidades necessários para construção de novas aprendizagens.

[...] "A avaliação formativa, por sua vez, fornece dados para aperfeiçoar o processo ensino e aprendizagem [...]" (MARCONDES, 2000, p.6). Portanto, se realiza ao longo dele e focaliza o desenvolvimento de competências e a formação de habilidades.

Por fim, a avaliação somativa "[...] classifica os resultados de aprendizagem de acordo com os níveis de aproveitamento estabelecidos [...]" (MARCONDES, 2000, p.6), procedendo-se no término da unidade na verificação do alcance dos objetivos preestabelecidos.

Os processos de avaliação diagnóstica, formativa e somativa, efetivam pela utilização de diferentes instrumentos que permitam a auto-avaliação, a avaliação interpares e outras estratégias (relatórios, provas escritas subjetivas / objetivas, observação sistemática, elaboração de textos / artigos, diferentes formas de pesquisa, entre outras), que possibilitem ao aluno analisar sua progressão nas aprendizagens e aos professores replanejarem intervenções oportunas que garantam a superação de problemas e dificuldades diversas.

Portanto, para que a proposta se efetive, é necessário que se avalie o desempenho do aluno em diferentes situações de aprendizagem.

\subsection{Organização das atividades}

O currículo integrado de Enfermagem foi estruturado em três séries modulares e uma série de internato, portanto, com quatro anos de duração ou 4.192 (quatro mil, cento e noventa e duas) horas, em período integral, ofertando 60 (sessenta) vagas.

Este currículo envolve os Centros: Centro de Ciências da Saúde (CCS), Centro de Ciências Biológicas (CCB), Centro de Letras e Ciências Humanas $(\mathrm{CCH})$, Centro de Ciências Agrárias (CCA), Centro de Ciências Exatas (CCE) e Centro de Educação, Comunicação e Artes (CECA).

A distribuição dos alunos, para atender aos princípios da Metodologia da Problematização, se dá em pequenos grupos (compostos por doze alunos), médios grupos (compostos por trinta alunos) e grande grupo (somando os sessenta alunos).

As atividades estão distribuídas em teóricas, práticas e ensino clínico. As disciplinas foram integradas em módulos e unidades interdisciplinares. Ao total são 13 (treze) módulos (UEL, 1999, p.16): 
1ª SÉRIE:

- MÓDULO I - A Universidade e o Curso de Enfermagem

- MÓDULO II - Processo Saúde - Doença

- MÓDULO III - Processo Saúde - Doença a partir do Núcleo Familiar

- MÓDULOIV - Prática Interdisciplinar e Multiprofissional 1

- MÓDULO V - Avaliação do Estado de Saúde do Indivíduo

\section{2ª SÉRIE:}

- MÓDULO VI - Introdução à Saúde do Adulto

- MÓDULO VII - Prática Interdisciplinar e Multiprofissional

- MÓDULO VIII - Saúde do Adulto I

- MÓDULO IX - Organização dos Serviços de Saúde e de Enfermagem

\section{SÉRIE:}

- MÓDULO X - Saúde do Adulto II

- MÓDULO XI - Prática Interdisciplinar e Multiprofissional 3

- MÓDULO XII - Da Concepção à Adolescência

\section{4ª SÉRIE:}

- MÓDULO XIII - Internato de Enfermagem

A elaboração do novo currículo do Curso de Enfermagem foi um trabalho árduo, que consumiu muitas horas de trabalho de docentes e discentes comprometidos com a melhoria contínua dos profissionais formados e que ingressam, a cada ano, no mercado de trabalho.

Mas, a elaboração foi apenas o primeiro momento de uma longa jornada. O processo de implementação reserva surpresas que precisam ser analisadas, pois nem sempre - ou quase sempre - o que se mostrou tão consistente no plano da concepção evidencia falhas e equívocos quando da consecução.

O compromisso com a formação de enfermeiros mais e mais competentes, mais e mais cônscios das responsabilidades inerentes ao seu fazer, exige daqueles encarregados de sua formação, o acompanhamento constante dos limites e possibilidades postos pelo contexto acadêmico/profissional.

Assim, acompanhar e analisar o processo de implementação do Currículo Integrado do Curso de Enfermagem é fundamental, determinar os fatores que vêm atuando enquanto dificultadores é essencial, bem como, reconhecer os aspectos facilitadores é de suma importância, pois, somente com base nos dados evidenciados é possível garantir a superação das dificuldades na edificação de uma prática pedagógica consistente com o perfil do profissional a ser formado.

\section{Referências}

BERBEL, N. A. N. Questões de Ensino. Notícia, Londrina, n. 3, out.1996.

Metodologia da Problematização: fundamentos e aplicações. Londrina: Ed. UEL, 1999.
BOGADO, M.L.G. et al. Projeto de Consolidação dos Novos Modelos Acadêmicos dos Cursos de Medicina e de Enfermagem. Londrina, 1998. Mimeografado.

DIAZ BORDENAVE, J. Alguns fatores pedagógicos. Trad. Maria Tereza Grane. Revista Interamericana de Educação de Adultos. v.2, n. 1-2, 1983.

BRASIL. Ministério da Educação. Lei de Diretrizes e Bases da Educação Nacional. Lei n.ㅇ․ 9.394 de 20/12/ 1996. [Brasília: Senado, 1996].

CHRISTOFOLLI, D.A.S. (Coord.). Análise Prospectiva do Curso de Graduação em Enfermagem da Universidade Estadual de Londrina: relatório final da fase diagnóstica. Londrina: CNPQ, 1990.

FLEURI, R. M. Educar para quê?. 9. ed. São Paulo: Cortez, 1997.

FREIRE, P. Educação como Prática da Liberdade. 3. ed. Rio de Janeiro: Paz e Terra, 1971.

A Pedagogia do Oprimido. 13. ed. São Paulo: Paz e Terra,1983.

Essa escola chamada vida. 3. ed. São Paulo: Ática, 1986.

Política e Educação: ensaios. 3. ed. São Paulo: Cortez, 1997.

GROSSI, E. P. Construtivismo Pós-Piagetiano. Um novo paradigma sobre aprendizagem. 4. ed. Rio de Janeiro: Vozes, 1993.

HIRAZAWA, S.A. Uma inovação no ensino de enfermagem na Universidade Estadual de Londrina: integração das disciplinas de saúde do adulto utilizando a metodologia da Problematização. Londrina, 1998. no prelo.

LIBÂNEO, J. C. Didática. São Paulo: Cortez, 1994.

MAGALHÃES, L. B. et al. Análise prospectiva do curso de enfermagem da Universidade Estadual de Londrina: o momento normativo. Londrina, 1993.

MARCONDES, M. A. S. Avaliação da aprendizagem. Londrina, 2000.

MISAEL, J. Projeto político-pedagógico. São Paulo, 1995. PEREIRA, A.M. Estratégias de ensino-aprendizagem. 18. ed. Petrópolis: Vozes, 1998.

SAVIANI, D. Educação : do senso comum à consciência filosófica. 12. ed. São Paulo: Cortez, 1996.

TAKAHASHI, O. C. et al. Currículo do Curso de Enfermagem. Londrina: Universidade Estadual de Londrina, 1995. Mimeografado.

UNIVERSIDADE ESTADUAL DE LONDRINA (UEL) Colegiado do Curso enfermagem. Currículo Integrado de Enfermagem da Universidade Estadual de Londrina. Londrina, 1999.

UNIVERSIDADE ESTADUAL DE LONDRINA (UEL) Departamento de Enfermagem. Internato de Enfermagem. Londrina, 2000.

VANNUCHI, M.T.O. et al. O Internato do Curso de Enfermagem da UEL: relato de uma experiência. Divulgação em Saúde para Debate, Londrina, n.15, p.2325, nov. 1996. 